\title{
Omuz çevresi nöral patolojilere yaklaşımda cerrahi teknikler ve klinik sonuçları
}

\author{
Surgical techniques and clinical results in neural pathologies around the shoulder
}

\author{
Mehmet Armangil , Yener Yoğun, Uğur Bezirgan
}

Ankara Üniversitesi Tıp Fakültesi, Ortopedi ve Travmatoloji Ana Bilim Dalı, El Cerrahisi Bölümü, Ankara

\begin{abstract}
Omuz çevresi nörolojik ve damarsal yaralanmalar çok yaygın olmamakla beraber gözden kaçmış, tanı almamış vakalar çok ciddi klinik sonuçlara ve medikolegal problemlere neden olabilmektedir. Ayrıca bu tür nörolojik yaralanmaların tedavisi hem hastalar için hem de cerrahlar için zorlu ve uzun bir süreçtir. Omuz çevresi nörolojik ve damarsal yaralanmalar genellikle motorlu taşıt kazaları, ateşli silah yaralanmaları, baş üstü fırlatma aktiviteleri içeren sporlarda meydana gelirler. Sinir hasarının mekanizmaları arasında doğrudan basınç, tekrarlayan mikrotravma, kompresyon veya gerilme kaynaklı iskemi yer alır. Aksiller, muskulokutan, supraskapular, uzun torasik sinirlerin yanı sıra supraklaviküler ve infraklaviküler brakiyal pleksus yaralanmalarından sonra omuz bölgeside belirgin klinik sendromlar oluşabilir. Bilinen kemik, yumuşak doku veya vasküler yaralanma yokluğunda bir hasta ağrı, güçsüzlük veya paresteziden şikayet ettiğinde sinir hasarından şüphelenilmelidir. Damarsal yaralanma varlığında veya yüksek enerjili travma sonrası şiddetli ağrı ve kas felci durumlarında cerrahi tedavi endikedir. Penetran yaralanması olmayan çoğu olguda sinir iyileşmesi 3-5 ay takip edilir. Klinik veya sinir iletim çalışmalarında iyileşme belirtisi olmadığında cerrahi tedavi endikedir. Bu makale, omuz çevresinde sık görülen sinir yaralanmalarının tedavisini ve cerrahi tedaviden sonraki klinik sonuçları tartışmaktadır.
\end{abstract}

Anahtar sözcükler: brakiyal pleksus yaralanması; omuz; sinir transferi; sinir yaralanması

\begin{abstract}
Although neurological and vascular injuries around the shoulder are not very common, overlooked and undiagnosed cases can cause very serious clinical results and medico-legal problems. In addition, the treatment of such neurological injuries is challenging and is a long period for both the patients and the surgeons. They often occur after motor vehicle accidents, gunshot wounds, in sports involving overhead throwing activities. Mechanisms of nerve damage include ischemia from direct pressure, repetitive microtrauma, compression, or stretch. After injuries of the axillary, musculocutaneous, suprascapular, long thoracic nerves, as well as the supraclavicular and infraclavicular brachial plexus, prominent clinical syndromes may occur around the shoulder. In the absence of bone, soft tissue, or vascular injury, nerve injury should be suspected when a patient complains of pain, weakness, or paresthesia. Surgical treatment is indicated in the presence of vascular injury or in cases of severe pain and muscle paralysis after high-energy trauma. In most cases without open trauma, nerve healing is followed for 3-5 months. Surgical treatment is indicated when there is no evidence of improvement in clinical or nerve conduction studies. This article discusses the management of common nerve injuries around the shoulder and the clinical outcome after surgical treatment.
\end{abstract}

Key words: brachial plexus injury; shoulder; nerve transfer; nerve injury

humerusa yakınlığı nedeniyle, bu yapılar herhangi bir omuz travmasından sonra yaralanabilmektedirler. ${ }^{[1]}$

Omuz eklemi vücudumuzdaki en fazla hareket açıklığına sahip eklemdir. Bu geniş eklem hareket açıklığı, eklem stabilitesini tehlikeye atar ve dolayısıyla omuz eklemini çıkıklara eğilimli hale getirir. ${ }^{[2]}$ Omuz eklemi bildirilen \%1,7 prevalansı ile en sık çıkık görülen majör eklemdir. ${ }^{[3]}$ Omuz eklemi ve brakiyal pleksusun anatomik yakınlığı nedeniyle, sinir yaralanmaları insidansı

İletişim / Contact: Prof. Dr. Mehmet Armangil•E-posta / E-mail: mehmetarmangil@yahoo.com

ORCID iD: Mehmet Armangil, 0000-0003-0433-0253 • Yener Yoğun, 0000-0002-3070-5509 • Uğur Bezirgan, 0000-0001-9053-8637

Geliş / Received: 10 Ocak 2022 • Kabul / Accepted: 6 Şubat 2022 
\%21-65 olarak bildirilmektedir. Hemen hemen tüm vakalarda, humerus başının aşağı doğru yer değiştirmesiyle traksiyona bağlı sinir patolojileri bildirilmiştir. ${ }^{[4]}$ Ayrıca omuz çevresinde travma dışı supraskapuler sinirin sıkışması sonucu supraspinatus ve infraspinatus kas güçsüzlüğü de oluşabilmektedir.

Akut omuz travması sonrası gelen bir hastayı başlangıçta değerlendirirken ve tedavi planlaması yaparken brakiyal pleksus, periferik sinirler, aksiller arter veya ven yaralanma potansiyeli göz önünde bulundurulmalıdır.

\section{SINIR YARALANMALARI}

Nörovasküler yaralanmalar ya anatomik yerleşime göre ya da sinir yaralanmasının derecesine göre sınıflandırılabilir. Anatomik olarak lezyonlar supraklaviküler veya infraklaviküler olarak tanımlanabilir.

\section{BRAKIYAL PLEKSUS YARALANMALARI}

Brakiyal pleksus tipik olarak beşinci servikal (C5) ve birinci torasik (T1), ara sıra dördüncü servikal (C4) veya ikinci torasik (T2) spinal sinirlerin katkısıyla oluşur. Üst ekstremiteyi innerve eden her sinir brakiyal pleksustan çıkar. Beş kök (root), üç gövde (turunkus), altı bölme (division), üç kordon ve uç dallarından oluşur. Brakiyal pleksus yaralanmaları, en sık motosiklet yaralanmaları olmak üzere, ciddi omuz kuşağı travmaları, ateşli silah yaralanmaları ve delici yaralanmalardan sonra oluşabilir. ${ }^{[5]}$

Motorsiklet yaralanmalarında meydana gelen traksiyon yaralanmalarında damarsal yaralanmalar da eşlik edebilir. Distal nabızların zayıflaması olmadan (ekstremite distalinde iyi bir dolaşım olsa bile) klavikula çevresinde belirgin morarma veya şişlik varlığında damar yaralanmalarından şüphelenilmelidir. Damar yaralanması mevcut olduğunda, tercihen aynı anda, acil vasküler ve sinir onarımıyla cerrahi müdahale endikedir. Ayrıca yüksek enerjili travma ve şiddetli ağrı veya kas felci içeren brakiyal pleksus yaralanmaları genellikle erken bir ameliyat gerektirir. Bu acil durum senaryolarının yokluğunda, hastalar cerrahi tedaviye karar vermeden önce genellikle 3-5 ay boyunca takip edilir. Klinik veya sinir iletim çalışmalarında iyileşme belirtisi olmadığında veya spontan iyileşmenin imkansız olduğu durumlarda cerrahi endikedir. ${ }^{\left[{ }^{[6]}\right.}$

\section{Cerrahi Yaklaşım}

Eksplorasyon (supraklaviküler ve infraklaviküler): Hasta supin pozisyonda ve aynı taraf ekstremitesi el masasında abduksiyon pozisyonda olmalıdır. Genellikle karşı taraf alt ekstremite, boyun ve gögüs kafesinin yarısından fazlası boyanmalıdır. Eğer proksimal pleksusun

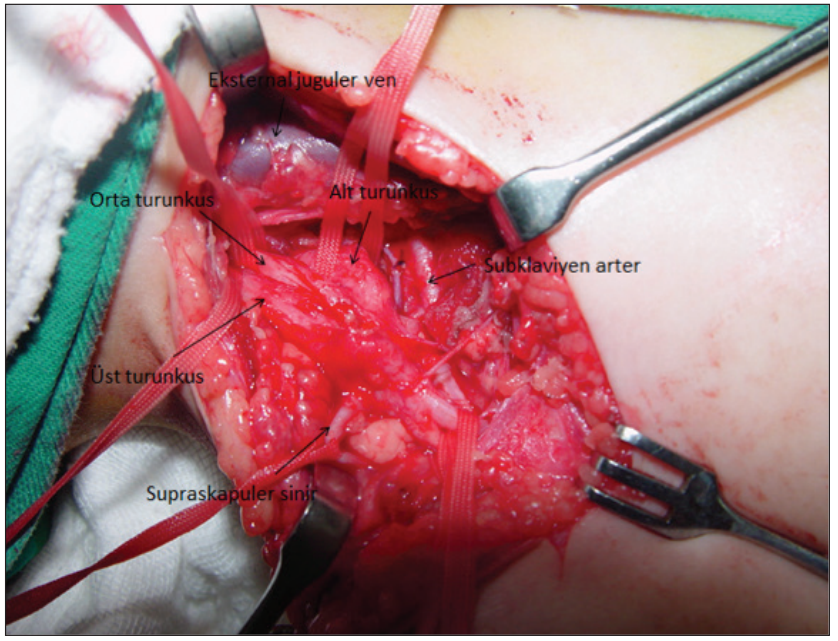

Şekil 1. Supraklaviküler yaklaşım.

anatomik rekonstrüksiyonu planlandıysa omuz addukte pozisyonunda iken supraklavikuler yaklaşım tercih edilir. Distal onarımlar için infraklavikuler yaklaşım uygundur.

Supraklavikuler yaklaşım için klavikulanın $1-2 \mathrm{~cm}$ yukarısından transvers kesi yapılır. Eğer kökler de eksplore edilecekse sternokleidomastoid (SKM) kasın arka sınırından kesi başa doğru uzatılır. Proksimal brakiyal pleksusu açığa çıkarmak için SKM kası ön tarafa, yağ yastığı (fat pad) üst tarafa ekarte edilir. Yağ yastığı disseke edilirken karşımıza çıkan supraklavikuler sinirlerin korunmasına dikkat etmek gerekir. Kökler ön ve orta skalen kaslar arasında bulunmaktadır ve frenik sinir de ön skalen kasın ön yüzünde longitudinal olarak geçmektedir (Şekil 1).

İnfraklavikuler yaklaşım için kesi klavikuladan koltuk altı ön duvarına, oradan da deltopektoral olarak uzatılabilir. Koltuk altı ön duvarında zikzak kesiler tercih edilir. Brakiyal pleksusa tam yaklaşım için pektoralis majör kası humerus yapışma yerinde kesilip mediale doğru ekarte edilmelidir. Pektoralis minör başlangıç yerine yakın yerde üste doğru ikiye ayrılır. Yaralanma bölgesini ve derecesini belirlemek için ameliyat esnasında geniş inceleme ve elektrik stimülatörüyle muayene yapılmalıdır. Yaralanmış sinir bölümü, normal sinir dokusundan daha kalın ve serttir ayrıca skar dokusu da belirgindir. Hasarlanan segmentin internal nörolizi, hem hasarlı skar dokusuna bağlı kompresyonu azaltır hem de fasiküllerin direkt olarak değerlendirilmesini sağlar. Daha ileri değerlendirme için sinir stimülatörü kullanılır. Sinir stimülatörüyle kas kasılması gözleniyorsa skarlı dokuda sadace nöroliz yapılır. Eğer stimülatörle kas kasılması gözlemlenmiyorsa nöroma rezeksiyonundan sonra sinir greftiyle onarım veya sinir transferleri yapılır (Şekil 2). 


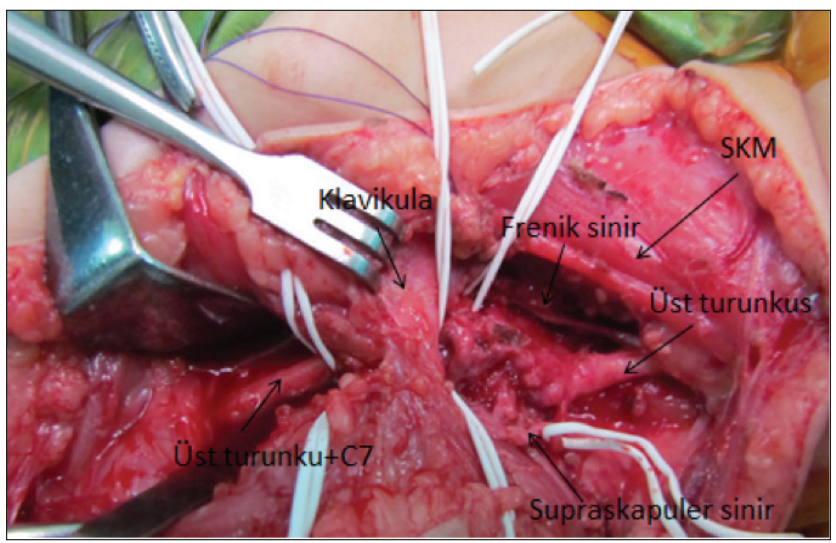

Şekil 2. Supraklaviküler ve infraklaviküler yaklaşım.

Sinir grefti ile onarım: Sinir grefti ile rekonstrüksiyon endikasyonları; direkt sinir yaralanmasında boşluk (gap) olması, nöroma rezeksiyonunun yapılması veya sinir transferi yapıldığı zaman alıcı ve verici (donör) sinir arasında boşluk olması sayılabilir (Şekil 3). Greft için sıklıkla medial antebrakiyal kutanöz ve sural sinir kullanılmaktadır. Biz klinik olarak daha uzun sinir grefti sağladığından ve iki ekibin aynı anda çalışmasına olanak sağladığından karşı taraf bacağın sural sinirini kullanmayı tercih ediyoruz. Karşı taraf ayak bilek distalinden lateral malleol ve aşil tendonu arasından longitudinal kesi yapılır. Distalde sural sinir bulunduktan sonra proksimale doğru diseke edilir. İhtiyaç duyulan sinir uzunluğuna göre proksimale doğru kesi uzatılır. Sural sinirin distaline işaret konulur ve her iki taraftan kesilir. Greftleme esnasında sural sinirin distal ucu proksimale gelecek şekilde tamir yapılır. Genellikle 2-3 kabloyla sinir grefti ile onarım yapılmalıdır. Genel olarak $6 \mathrm{~cm}$ 'den uzun olmayan sinir greftlerin başarısı daha yüksektir.

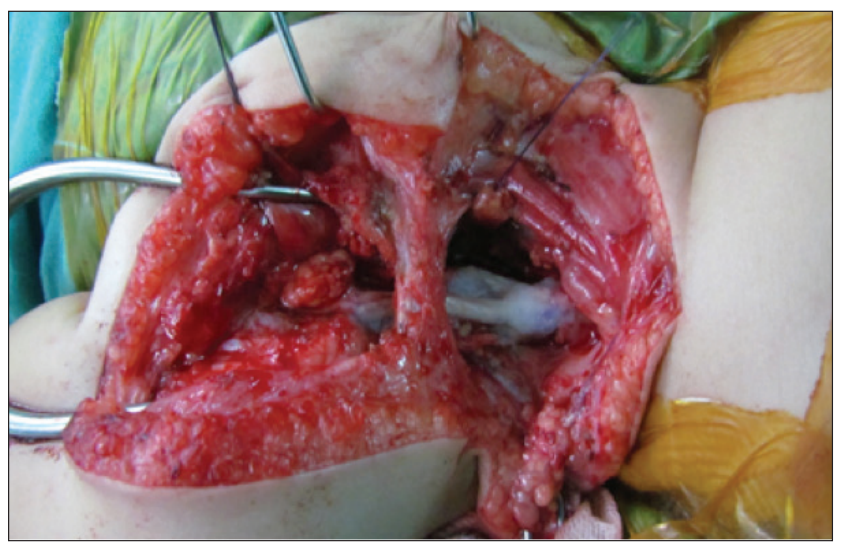

Şekil 3. Nöroma eksizyonu sonrası sural sinir grefti ile onarım yapılan hastanın tamir sonrası görüntüsü. Sinir greftlemesi sonrası onarım yerine fibrin yapıştırıcı uygulandı.

\section{AKSILLER SINIR YARALANMASI}

Aksiller sinir, omuz travmalarında en sık yaralanan sinirdir ve sıklıkla brakiyal pleksus yaralanmasıyla ilişkilidir. Aksiller sinir hasarı, omuz çıkığının en sık görülen komplikasyonudur. ${ }^{[1]}$ Omuz çıkıklarının elektromiyografi/ sinir iletim çalışmalarında elektromiyografi/sinir iletim çalışması (EMG/Siç) \%54 oranında subklinik aksiller sinir lezyonu saptanabilmektedir. ${ }^{[7]}$ Bu yüksek yaralanma oranına rağmen, aksiller sinir lezyonlarının çoğu cerrahi dışı tedaviyle iyileşir. ${ }^{[8]}$ Elli yaşından büyük hastalarda ve 12 saatten uzun süren çıkık durumlarında kalıcı sinir hasarı oluşma ihtimali daha yüksektir. ${ }^{[1]}$ Futbol ve hokey sporlarında künt travma sonrasında deltoid kasının derin liflerine kompresyon sonucu aksiller sinir yaralanması olabileceği de bildirilmiştir. ${ }^{[9]}$

Omuz travmasını takip eden ilk üç ay içinde çoğu aksiller sinir yaralanmasında konservatif tedavi yaklaşımı endikedir. Üç ila dört haftada EMG/Siç yapılabilir. Tedavide ilk konservatif yaklaşım savunulur çünkü çoğu hastada ameliyatsız tedaviyle iyi sonuçlar alınır. Hastalarda altı ila dokuz ay arasında herhangi bir klinik düzelme veya EMG'de iyileşmesi olmazsa, hastalar nöroliz ve muhtemel sinir grefti ile cerrahi eksplorasyon için sevk edilmelidir. Aksiller sinir felci geç başvurularında (12 aydan fazla), sinir onarımının sonucu kötüdür. ${ }^{[1]}$

Aksiller sinirin izole yaralanmasında farklı tedavi seçenekleri mevcuttur. Geleneksel olarak posterior kord distalindeki izole aksiller lezyonlar için tercih edilen tedavi sinir greftiyle cerrahi onarımdır. Bu tedavi potansiyel olarak aksiller sinirin hem ön hem de arka dallarının iyileşmesini sağlar. 1948'de Lurje, servikal 5-6 (C5-C6) seviyelerinde lezyonu olan bir hastada radial sinirin triseps fasiküllerini sinir grefti olmaksızın aksiller sinire transfer etme tekniğini tanımladı. ${ }^{[10]}$ Nath ve Mackinnon daha sonra Lurje'nin tekniğini kullanarak beş hastada tatmin edici sonuçlar bildirdiler. ${ }^{[11]}$ Daha sonra triseps kasının hem lateral hem de medial başını innerve eden radial sinir liflerinin verici (donör) olarak kullanılabileceği bildirilmiştir. ${ }^{[12,13]}$ Alıcı sinir için uygun boyutta olması, sabit dallanma noktası ve alıcı sinire yakınlığı nedeniyle trisepsin uzun başına giden radyal siniri genellikle tercih edilir. Ayrıca trisepsin uzun başının dirsek ekstansiyonuna en az katkı vermesi de bir diğer tercih edilme sebebidir. ${ }^{[14]}$

\section{Cerrahi Yaklaşım}

Radyal sinirin (trisepsin uzun başına giden dalı) aksiller sinire transferi (posterior yaklaşım): Bu sinir transfer için triseps kas gücü en az M4 olmalıdır. Hasta, etkile- 
nen üst ekstremitenin altında bir kum torbasıyla sırtüstü pozisyona getirilir. Etkilenen kol göğsün karşısına yerleştirilir, böylece omzun arka yüzü ortaya çıkar.

Arka deltoidin sınırı boyunca yaklaşı $12 \mathrm{~cm}$ 'lik kavisli bir kesi yapılır. Deltoid atrofik olduğu için posterior yapışma yerini spina skapuladan ayırmaya gerek kalmadan kolayca yükseltilebilir. Trisepsin uzun ve lateral başları arasındaki aralık, daha sonra kuadrilateral boşluğu ve trianguler aralığı ortaya çıkarmak için uzatıır. Teres major, kuadrilateral boşluğu trianguler aralıktan ayıran anahtar yapıdır. Daha sonra, trianguler aralıktaki radyal sinir izole edilir. Genellikle teres majör alt kenarının yaklaşık $1 \mathrm{~cm}$ proksimalinde çıkan sinirin ilk dalı, triseps uzun başının siniridir.

Aksiller sinire kuadrilateral boşlukta posterior sirkumfleks humeral arter ve ven eşlik eder. Aksiller sinir boşluktan çıktıktan sonra teres minöre bir dal verir ve daha sonra 1 ile 3 ön dala ve 1 arka dala ayrılır. Deltoid kasın ana motor dalı olan ön dal(lar) mümkün olduğunca proksimale doğru disseke edilir. Sinirlerin elektriksel uyarımı, trisepslerin güçlü kasılmalarını doğrulamak için kullanılır. Aynı zamanda deltoid adalesinde kasılmamanın olmaması da önemlidir. Triseps uzun başına giden sinirin (donör) kasa girmeden hemen önce mümkün olduğunca distalden, aksiller sinirin (alıcı) ön dalı ise mümkün olduğunca proksimalden kesilip nörotize edilir.

\section{Klinik Sonuçlar}

İzole aksiller sinir yaralanması olan ve radyal sinirin trisepsin uzun başına giden dalının aksiller sinire transferi ile tedavi edilen 21 hastalık seride, ortalama M4 deltoid gücü elde ettiklerini belirtilmiştir. ${ }^{[15]}$ Birkaç çalışmada da izole aksiller sinir hasarının radyal sinir transferiyle başarılı bir şekilde tedavi edilebileceğini gösterilmiştir. ${ }^{[16,17]}$

Okazagi ve ark. spinal aksesuar sinirin supraskapular sinire ve triseps dalının uzun başına giden radyal sinirin aksiller sinire transfer yaptıkları yedi hastadan oluşan seride, tüm hastalarda M4 deltoid fonksiyonu ortalama $124^{\circ}$ abduksiyon elde etmişlerdir. ${ }^{[8]}$ Bertelli ve ark. C5-C6 yaralanması olan 10 hastada ikili sinir transferlerinin sonuçlarını yayınlamışlardır. Üç hasta M4 ve yedi hastada M3 gücünde omuz abduksiyonu elde etmişlerdir. ${ }^{[18]}$ Ortalama abduksiyon $92^{\circ}$ ve ortalama dış rotasyon ise $93^{\circ}{ }^{\prime}$ di. $^{[18]}$ Leechavengvongs Somsak ve ark. yaptığı C5-C6 yaralanmalı 15 hastadan oluşan başka bir seride; 13 hastanın M4 deltoid fonksiyonu, iki hastanın ise M3 deltoid fonksiyonu kazandığını bildirmişlerdir. Hastaların ortalama omuz abduksiyonu $115^{\circ}$ ve ortalama dış rotasyon $97^{\circ}$ olarak bildirmişlerdir. ${ }^{[19]}$
Interkostal sinirlerin aksiller sinire transferi: C5 ila C7 kök avülsiyon yaralanmalarında, triseps zayıflar veya felç olur. Bu vakalarda radyal sinir donör sinir olarak kullanılmaya uygun değildir. Bu durumda interkostal sinirler, aksiller sinir yaralanmaları için potansiyel donör sinirlerdir.

Interkostal sinirin ortaya çıkarılması için beşinci kaburganın alt sınırı boyunca parasternal sınırdan midaksiller hatta uzanan eğrisel bir kesi yapılır. Pektoralis majör ve minör, dördüncü ila altıncı kaburgaları ortaya çıkarmak için kaldırılır. Verici olarak genellikle dördüncü ve beşinci interkostal sinirler kullanılır. Her kaburganın ön fasyası kesilir. Periost elevatörü, her bir kaburgayı internal ve eksternal interkostal kaslardan ayırmak için kullanılır. Her interkostal sinir, iç interkostal kasın altında tanımlanır. Diseksiyon parasternal sınırdan midaksiller hatta kadar devam eder. Interkostal sinirlere, damarlara veya plevraya zarar vermemek için büyük özen gösterilmelidir. Midaksiller hattın hemen önünde, interkostal sinirin hareketliliğini arttırmak için her bir interkostal sinirin duyu dalı tanımlanır ve kesilir.

Aksiller sinirin posterior yaklaşımla açığa çıkarılması önceki başlıkta anlatılmıştır. Aksiller sinire ulaşmak için interkostal sinirler aksilladaki cilt altı bir tünelden geçirilir. Transferi gerçekleştirdikten sonra, nörotizasyonda aşırı gerilim olmadığından emin olmak için intraoperatif olarak tam pasif omuz abduksiyon yapılır ve gerginlik kontrol edilir (Şekil 4).

\section{Klinik Sonuçlar}

Samard zić ve ark. aksiller sinire interkostal sinir transferi ile \%33 oranında mükemmel ve iyi sonuçlar bildirmişlerdir. ${ }^{[20]}$ Malungpaishrope ve ark. da supraskapular sinire spinal aksesuar sinir transferi ve anterior aksiller sinire iki interkostal sinir transferi yapılan 10 hastada ortalama $69^{\circ}$ lik bir omuz abduksiyonu olduğunu belirtmişlerdir. ${ }^{[21]}$

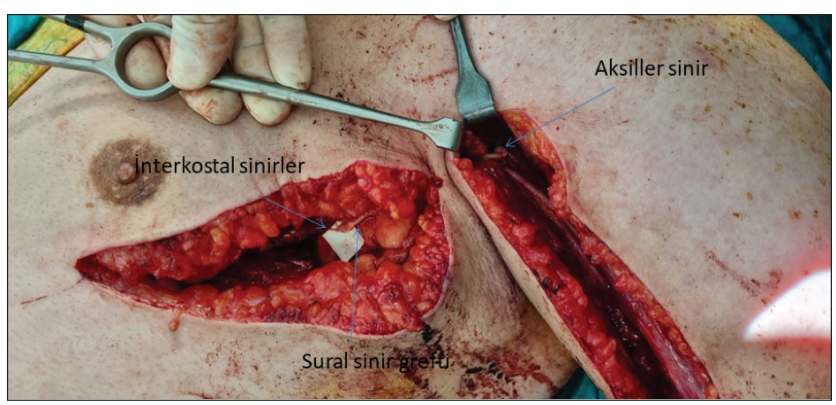

Şekil 4. Interkostal sinirlerin sural sinir grefti ile aksiller sinire transferi. 


\section{SUPRASKAPULAR SINIR YARALANMASI}

Supraskapular sinir hem duyusal hem de motor lifleri içeren bir sinirdir. Brakiyal pleksusun üst gövdesinden, özellikle C5 ve C6 köklerinden ve bazen de \%50'ye varan oranda C4 kökünden dal alır. Posterior servikal üçgenden laterale doğru ilerler ve supraskapular çentiğe ulaşır. ${ }^{[6]}$

Supraskapular sinirin yaralanma mekanizmaları; Erb noktasıyla supraskapular çentik arasında sinirin gerilmesinden kaynaklanan traksiyon, sürtünme, doğrudan yaralanma ve baş üstü spor aktivitelerinde tekrarlayan mikrotravmayı içerir. Supraskapular sinir sıkışmasının bir başka nedeni de spinoglenoid çentikte bir ganglion kistidir. Bu kistler posterior labral yaralanma ve posterior omuz instabilitesiyle ilişkili görünmektedir. ${ }^{[22]}$

Supraskapular sinir, supraspinatus ve infraspinatus kaslarını innerve eder. Distal yaralanmalarda sadece infraspinatus kası etkilenir ve kolun dış rotasyonunda zayıflık olur. Supraspinatus da etkilenmişse, o zaman kol elevasyonunda, özellikle $90^{\circ}$ ile $180^{\circ}$ arasında ek bir zayıflık vardır. Öykü ve diğer olası bulgular arasında kronik baş üstü sporlar, omuz travması veya cerrahi öyküsü, masif ve geri çekilmiş rotator manşet yırtığı, supraspinatus ve infraspinatus atrofisi, akromiyoklaviküler eklemin ve/veya eklem hattının posteromedialinde hassasiyet bulunur. Supraskapuler sinirin yaralanması veya nöropatisi düşünüldüğünde, elektrofizyolojik çalışmalar ve manyetik rezonans görüntüleme (MRG) her zaman kullanılmalıdır. Elektromiyografi (EMG) ve sinir iletim hızı çalışmaları, iletim gecikmesi ve denervasyon belirtileri gösterebilir. MRG'de, labral veya rotator manşet yırtıklarının, ganglion kistlerinin ve diğer kompresif lezyonların tanısında faydalı olacaktır. ${ }^{[23]}$

Özellikle aşırı kullanım sonrası supraskapuler sinir nöropatisi olan hastaların çoğu için başlangıç tedavisi cerrahi olmamalıdır. Aktivite modifikasyonu, nonsteroid antiinflamatuar ilaçlar ve omuz ekleminin tam hareket açıklığını korumak için bir fizik tedavi protokolü önerilir. ${ }^{[6]}$ Çoğu hastada fonksiyonel iyileşme ve ağrı rahatlaması sağlansa da, semptomları uzamış (3-6 ay), masif rotator manşet yırtığı veya ganglion kisti gibi yer kaplayan bir lezyonu olanların konservatif yaklaşımdan fayda görmeleri olası değildir. ${ }^{[24]}$

\section{Cerrahi Yaklaşım}

Spinal aksesuar sinirin supraskapular sinire transferi: Spinal aksesuar sinir, sternokleidomastoid ve trapezius kaslarını innerve eden saf bir motor sinirdir. Donör sinir olarak kullanıldığında, trapeziusun bir miktar işlevini korumak için üst ve orta trapezius dallarını korurken dis- tal dalı izole etmek önemlidir. Bu sinir transferinin fonksiyonel amacı, kolun bir miktar abduksiyonunu ve ileri fleksiyonunu yeniden kazanmaktır. Omuzun dış rotasyonu değişken derecelerde geri kazanılabilir ve bu ancak skapula stabil olduğunda elde edilebilir.

$\mathrm{Bu}$ sinir transfer için trapezius kas gücü en az M4 olmalıdır. Hasta, etkilenen üst ekstremitede skapula altına bir kum torbası konularak sırtüstü yatırılır. Baş karşı tarafa çevrilir ve venöz konjesyonu azaltmak için vücudun üst kısmı hafifçe kaldıııır (şezlong pozisyonu). Intraoperatif elektrik stimülasyonuna izin vermek için uzun etkili paralitik ajanlar ve kas gevşetici ameliyat esnasında kullanılmamalıdır.

Supraklaviküler pleksusun eksplorasyonu için "V" şeklinde bir insizyon yapılır. Trapeziusun lateral kısmı distal klavikuladan 1 ila $2 \mathrm{~cm}$ ayrilır. Diseksiyon daha sonra trapez kasının ön yüzeyinde klavikulanın birkaç santimetre yukarısında gerçekleştirilir. Siniri tespit etmek için dönüm noktası, sinire eşlik eden enine servikal damarlardır. Spinal aksesuar sinirin distal kısmını belirlemek için damarların etrafında bir elektrik stimülatörü kullanılabilir. Bu sinir, uyarıldığında herhangi bir kas tepkisi oluşturmayacak olan servikal pleksustan gelen küçük dallarla karıştırılmamalıdır. Spinal aksesuar sinir mümkün olduğu kadar distale doğru diseke edilmelidir. Supraskapular sinir normalde üst gövdeden (turunkus) klavikulanın 2 ila $3 \mathrm{~cm}$ yukarısında bulunur. Supraskapular sinir daha sonra distalden proksimale doğru izlenir ve donör spinal aksesuar sinir ile koaptasyondan önce üst gövdeden ayrilır.

\section{Klinik Sonuçlar}

Klinik sonuç, yaralanma tipi ve gerçekleştirilen sinir transferlerinin sayısı dahil olmak üzere birçok faktörden etkilenir. Yaralanma ne kadar kapsamlı olursa, omuz fonksiyonunun sonucu o kadar kötü olur ve rapor edilen ortalama omuz abduksiyonu $45^{\circ}$ ile $122^{\circ}$ arasında değişir. ${ }^{[25]}$ Dış rotasyonun sonuçları tutarsız olmakla beraber, $0^{\circ}$ 'den $118^{\circ}$ ye kadar değişen hareket açıklıkları bildirilmiştir. ${ }^{[26,27]}$

\section{MUSKULOKUTAN SINIR YARALANMASI}

İzole muskulokutan sinir hasarı çok nadir görülür. Sıklıkla brakiyal pleksus yaralanmalarıyla ilişkilidir. Penetran yaralanma veya korakoide künt travma sonucu izole yaralanmalar meydana gelebilir. Glenohumeral eklem çıkığını takiben muskulokutanöz sinirde traksiyonu yaralanması görülebilir. Çoğu muskulokutan sinir palsisi, dirsek fleksiyonunda zayıflık, lateral önkol boyunca 
ağrı ve uyuşukluk ile birlikte karışı motor ve duyusal eksiklik olarak ortaya çıkar. Nadiren, biseps ve brakialis kası arasında sinir sıkıştıkça dirsek ekstansiyonuyla şiddetlenen saf bir duyu nöropatisi oluşur. Bir muskulokutan sinir yaralanması tanısı konmuşsa, EMG/Siç ile üç ila dört haftadan başlayarak belli aralıklarla hasta takibe alınır. Altı ila dokuz ayda dirsek fleksiyonunda düzelme olmazsa cerrahi eksplorasyon ve sinir grefti interpozisyonu ile nöroliz denenmelidir. Hastalarda sinir tamiri mümkün değilse sinir transferi yapılabilir. Ulnar sinirin fleksör karpi ulnarise giden fasikülleri biseps kasına giden muskulokutan sinirin dalına transfer edilebilir. Ayrıca median sinirin el fleksör karpi radialise giden fasikülleri de brakiyalis kasına giden muskulokutan sinirin dalına transfer edilebilir. Hastalar sinir iyileşmesi olmadan geç (travmayı takiben bir yıldan fazla) tanı aldığında, tedavi seçeneği olarak tendon transferleri düşünülmelidir. ${ }^{[1]}$

\section{Cerrahi Yaklaşım}

Ulnar sinirin (Fleksör karpi ulnarise 'FKU' giden dalı) muskulokutan sinire (biseps dalına) ve median sinirin (Fleksör karpi radialise 'FKR' giden dalı) muskulokutan sinire (brakiyalis dalına) transferi: Oberlin, dirsek fleksiyonunu düzeltmek için ulnar sinirin FKU fasiküllerini kullanarak muskulokutan sinirin biseps dalına transferini tarif etmiştir ${ }^{[28]}$ Hasta supin poziyonunda yatırılır ve kol $90^{\circ}$ abduksiyona alınır. FKU fasiküllerini belirlemek için daha önce anlatılan infraklavikuler yaklaşım kullanılır. Kol medialinde biseps ve triseps kası arasından uzunlamasına kesi yapılır. Biseps kası kibarca ekarte edildikten sonra nörovasküler yapılar eksplore edilir. Muskulokutan sinirin bulunup bisepse giden dalı kas girişine kadar disseke edilir. Ardından biseps ve brakiyalis kasları arasından daha posteriorda ulnar sinir bulunur. FKU'ya giden sinir lifleri genellikle ulnar sinirin lateral tarafında bulunur ve internal nöroliz yapıldıktan sonra bir sinir stimülatörü kullanılarak FKU'yu uyardığı doğrulanır. Sinir stimulatörü ile FKU'nun kasıldığının görülmesi önemlidir. Aynı derecede önemli olan, kalan ulnar sinir fasiküllerinin stimülasyonu ile, el intrensek kaslarında, dördüncü ve beşinci parmakların fleksör digitorum profundusunda kasılmanın görülmesidir. Transferde ulnar sinirin yaklaşık \%20'si kullanılır. Ulnar sinirin FKU ya giden dalı distalden kesilip iki sinirin nörotizasyonu yapılır.

En medialde median sinir bulunduktan sonra brakiyalis kası seviyesine kadar distale doğru disseksiyon yapılır. Muskulokutan sinirin brakialis kasına giden dalı bulunur. Ardından median sinire internal nöroliz yapılıp FKR'ye giden dalları sinir stimülatörü yardımıyla bulunur. Bazen fleksör digitorum superfisialise giden sinir fasikülleri de bu transfer için kullanılır. Median sinirin FKR'ye giden

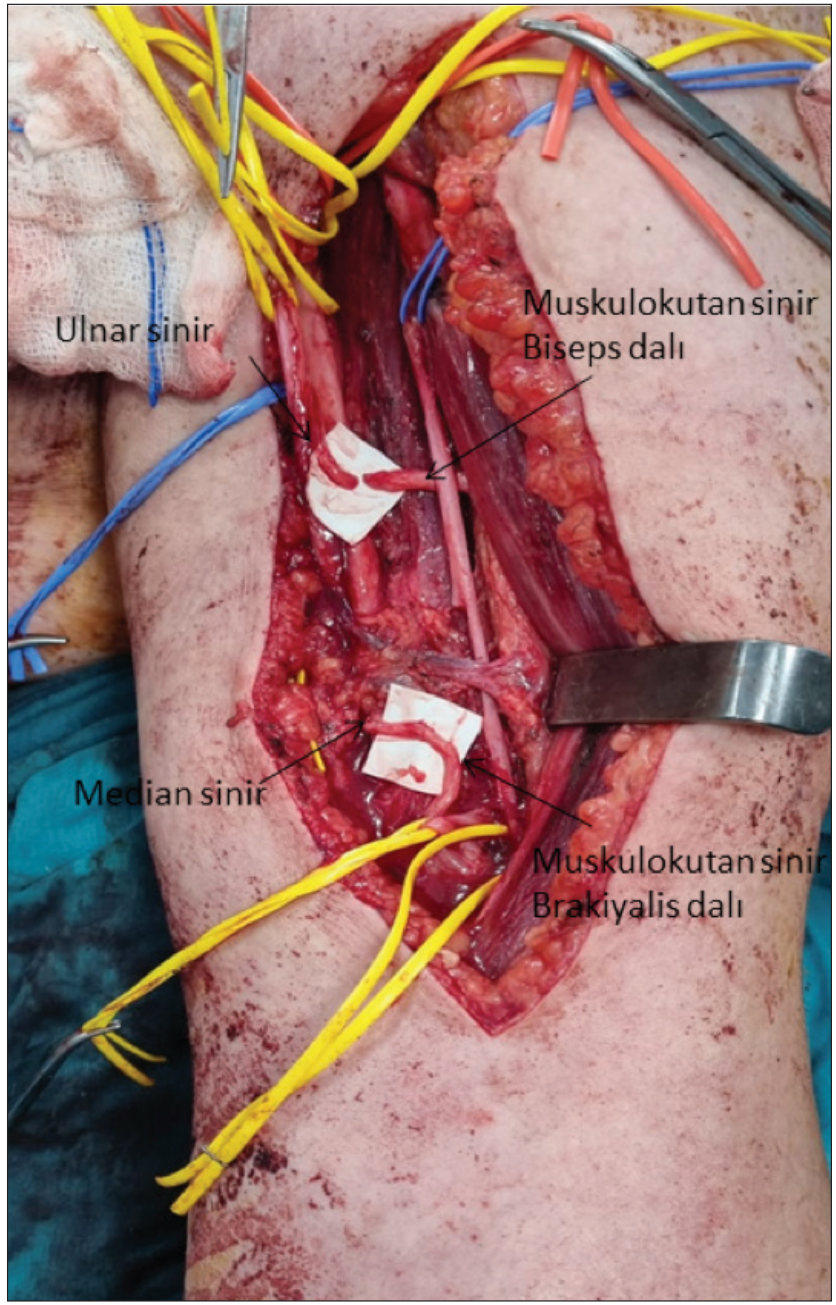

Şekil 5. Travmatik brakiyal pleksuslu hastanın hem ulnar hem median sinirin muskulokutan sinire transferi (ulnar sinirin FKU'ya giden dalı $\rightarrow$ muskulokutan sinirin biseps dalına, median sinirin FKR'ye giden dalı $\rightarrow$ muskulokutan sinirin brakiyalis dalına transferi).

(FKU: Fleksör karpi ulnaris, FKR: Fleksör karpi radialis).

fasiküller proksimale doğru disseke edilir ve distalden kesilir. Brakiyalis kasına giden muskulokutan sinirin dalı da mümkün olduğunca distalden kesilir ve transfer yapılır. Kalan median sinir liflerinin de çalıştığı sinir stimülatörüyle kontrol edilir (Şekil 5).

\section{Klinik Sonuçlar}

Verdins ve ark., Oberlin sinir transferi yaptıkları 10 hastalık vaka serisinde, altı hastada M5, dört hastada M4 dirsek fleksiyonu elde ettiklerini bildirmişlerdir. ${ }^{[29]}$ Venkatramani ve ark., Oberlin sinir transferi yaptıkları 15 vakalık seride 13 hastada M4/5 gücünde dirsek fleksiyonu elde ettiklerini bildirmişlerdir. ${ }^{[30]}$ Gutowsky ve Liverneaux, Oberlin sinir transferinin yaşlı hastalarda daha kötü sonuçların olduğunu ayrıca yaralanmadan 
cerrahiye kadar geçen süre uzadıkça sonuçların kötüleştiğini bildirmişlerdir. ${ }^{[31,32]}$

\section{UZUN TORASIK SINIR YARALANMASI}

Serratus anterior kasının felci; ağrıya, omuz hareketlerinde kısıtlılığa ve skapulanın kanatlanmasına neden olur. Kas, C5'ten C7'ye kadar olan sinir liflerini alan uzun torasik sinir tarafından innerve edilir. C5-6 brakiyal pleksus yaralanmalı bazı hastalar ve $\mathrm{C} 7$ kökünde kısmi yaralanması olan kişilerde kas felci veya zayıflığı görülebilir. Bu durumlarda saf motor sinir olan ve $\mathrm{C} 7$ ve $\mathrm{C} 8$ köklerinden sinir liflerini alan torakodorsal sinir hala korunur ve transfer için donör sinir olarak kullanılabilir. ${ }^{[33]}$

\section{Cerrahi Yaklaşım}

Torakodorsal sinirin uzun torasik sinire transferi: Latissimus dorsi kası en az M4 gücüne sahip olmalıdır. Hasta, etkilenen kürek kemiğinin altına bir kum torbası ile sırtüstü yatırılır. Kol göğsün karşısına yerleştirilir.

Latissimus dorsinin ön kenarına denk gelecek şekilde arka koltuk altı kıvrımı boyunca $12 \mathrm{~cm}$ 'lik uzunlamasına bir kesi yapılır. Latissimus dorsi ve pektoralis majör arasındaki aralığa girmek için künt diseksiyon yapılır. Latissimus dorsi daha sonra torakodorsal ve uzun torasik sinirleri ortaya çıkarmak için arkaya doğru çekilir. Latissimus dorsinin ön sınırı etrafındaki diseksiyon torakodorsal sinir ve damarları ortaya çıkaracaktır. Sinirin medial ve lateral olmak üzere iki ana dalı vardır. Lateral dal kasın lateral sınırına paralel uzanır, medial dal ise üst kas sınırına paralel olarak nörovasküler hilusta lateral daldan $45^{\circ}$ lik bir açıyla ayrılır. Daha güçlü kasılmaya neden olan dalı seçmek için sinir stimülatörü kullanılır. Seçilen dal, genellikle lateral dalı olur ve mümkün olduğunca distalden kesilir.

Uzun torasik sinir, lateral göğüs duvarında midaksiller çizginin biraz önünde yer alan ince gümüş beyazı şeklinde bir yapı olarak görünür. Bazı durumlarda bu bölgenin etrafındaki yağ dokusu siniri gizleyebilir ve diseksiyonunu zorlaştırabilir. Yine bu durumda parmakları kullanarak künt diseksiyon yapmak faydalıdır. Üstteki fasya serbest bırakılır ve eşlik eden, kolayca kanayan ince damarlara zarar vermemeye dikkat etmek gerekir. Serratus anterior paralizi doğrulandıktan sonra, yeniden innerve edilebilen kas miktarını maksimuma çıkarmak ve torakodorsal sinir ile gerilimsiz bir nörotizasyonu için sinir mümkün olduğunca proksimalden kesilir.

\section{Klinik Sonuçlar}

Novak ve Mackinnon, idiyopatik serratus anterior kas güçsüzlüğü olan bir hastada torakodorsal sinirin medial dalını uzun torasik sinire transfer ettiler. Yedi yıllık takipte skapulada kanatlanma olmaksızın omuzda tam hareket açıklığı olduğunu bildirdiler. ${ }^{[34]}$ Uzun torasik sinire torakodorsal sinir transferi yapılan C5-C6 brakiyal pleksus yaralanmalı beş hastalık seride, hastalar ortalama 28 aylık takip edilmiş iki hastada kanat skapula olmadığını, üç hastada hafif kanat skapula olduğunu belirtilmiştir. Omuz abduksiyonunun ortalama $134^{\circ}$, ortalama dış rotasyonun ise $124^{\circ}$ olduğu, ayrıca hiçbir hastada torakodorsal sinirin bir dalının alınmasından kaynaklanan herhangi bir işlevsel eksiklikten bahsedilmemiştir. ${ }^{[35]}$

\section{KAYNAKLAR}

1. Zarkadas PC, Throckmorton TW, Steinmann SP. Neurovascular injuries in shoulder trauma. Orthop Clin North Am 2008;39(4):483-90. Crossref

2. Shah A, Judge A, Delmestri A, Edwards K, Arden NK, Prieto Alhambra $D$, et al. Incidence of shoulder dislocations in the UK, 1995-2015: a population-based cohort study. BMJ Open 2017;7(11):e016112. Crossref

3. Shah R, Chhaniyara P, Wallace WA, Hodgson L. Pitch-side management of acute shoulder dislocations: a conceptual review. BMJ open Sport Exerc Med 2017;2(1):e000116. Crossref

4. Tiefenboeck TM, Zeilinger J, Komjati M, Fialka C, Boesmueller $\mathrm{S}$. Incidence, diagnostics and treatment algorithm of nerve lesions after traumatic shoulder dislocations: a retrospective multicenter study. Arch Orthop Trauma Surg 2020;140(9):117580. Crossref

5. Narakas AO. The treatment of brachial plexus injuries. Int Orthop 1985;9(1):29-36. Crossref

6. Kokkalis ZT, Pantzaris N, Iliopoulos ID, Megaloikonomos PD, Mavrogenis AF, Panagiotopoulos E. Nerve Injuries around the Shoulder. J Long Term Eff Med Implants 2016;26(4). Crossref

7. Travlos J, Goldberg I, Boome RS. Brachial plexus lesions associated with dislocated shoulders. J Bone Joint Surg $\mathrm{Br}$ 1990;72(1):68-71. Crossref

8. Okazaki M, Al-Shawi A, Gschwind CR, Warwick DJ, Tonkin MA. Outcome of axillary nerve injuries treated with nerve grafts. J Hand Surg European Vol 2011;36(7):535-40. Crossref

9. Gutkowska O, Martynkiewicz J, Urban M, Gosk J. Brachial plexus injury after shoulder dislocation: a literature review. Neurosurg Rev 2020;43(2):407-23. Crossref

10. Lurje A. Concerning surgical treatment of traumatic injury to the upper division of the brachial plexus (Erb's type). Ann Surg 1948;127(2):317. Crossref

11. Nath RK, Mackinnon SE. Nerve transfers in the upper extremity. Hand Clin 2000;16(1):131-9. Crossref

12. Kostas-Agnantis I, Korompilias A, Vekris M, Lykissas M, Gkiatas I, Mitsionis G, et al. Shoulder abduction and external rotation restoration with nerve transfer. Injury 2013;44(3):299-304. Crossref 
13. Bertelli JA, Ghizoni MF. Nerve transfer from triceps medial head and anconeus to deltoid for axillary nerve palsy. J Hand Surg Am 2014;39(5):940-7. Crossref

14. Uerpairojkit $\mathrm{C}$, Ketwongwiriya S, Leechavengvongs $\mathrm{S}$, Malungpaishrope K, Witoonchart K, Mekrungcharas N, et al. Surgical anatomy of the radial nerve branches to triceps muscle. Clin Anat 2013;26(3):386-91. Crossref

15. Lee J-Y, Kircher MF, Spinner RJ, Bishop AT, Shin AY. Factors affecting outcome of triceps motor branch transfer for isolated axillary nerve injury. J Hand Surg Am 2012;37(11):2350-6. Crossref

16. Zuckerman SL, Eli IM, Shah MN, Bradley N, Stutz CM, Park TS, et al. Radial to axillary nerve neurotization for brachial plexus injury in children: a combined case series. J Neurosurg Pediatr 2014;14(5):518-26. Crossref

17. Wheelock M, Clark TA, Giuffre JL. Nerve transfers for treatment of isolated axillary nerve injuries. Plast Surg 2015;23(2):77-80. Crossref

18. Bertelli JA, Ghizoni MF. Reconstruction of C5 and C6 brachial plexus avulsion injury by multiple nerve transfers: spinal accessory to suprascapular, ulnar fascicles to biceps branch, and triceps long or lateral head branch to axillary nerve. J Hand Surg Am 2004;29(1):131-9. Crossref

19. Leechavengvongs $\mathrm{S}$, Witoonchart $\mathrm{K}$, Uerpairojkit $\mathrm{C}$, Thuvasethakul P, Malungpaishrope K. Combined nerve transfers for C5 and C6 brachial plexus avulsion injury. J Hand Surg Am 2006;31(2):183-9. Crossref

20. Samard zić M, Rasulić L, Gruji cić D, Mili cić B. Results of nerve transfers to the musculocutaneous and axillary nerves. Neurosurgery 2000;46(1):93-103. Crossref

21. Malungpaishrope K, Leechavengvongs S, Witoonchart K, Uerpairojkit C, Boonyalapa A, Janesaksrisakul D. Simultaneous intercostal nerve transfers to deltoid and triceps muscle through the posterior approach. J Hand Surg Am 2012;37(4):677-82. Crossref

22. Clitherow HDS, Bain GI. Neurovascular Injuries with Shoulder Surgery. In: Normal and Pathological Anatomy of the Shoulder. Springer; 2015. p. 353-67. Crossref

23. Piasecki DP, Romeo AA, Bach BR, Nicholson GP. Suprascapular neuropathy. JAAOS-Journal Am Acad Orthop Surg 2009;17(11):665-76. Crossref

24. Martin SD, Warren RF, Martin TL, Kennedy K, O'BRIEN SJ, Wickiewicz TL. Suprascapular neuropathy. Results of non-operative treatment. JBJS 1997;79(8):1159-65. Crossref
25. Bertelli JA, Ghizoni MF. Transfer of the accessory nerve to the suprascapular nerve in brachial plexus reconstruction. J Hand Surg Am 2007;32(7):989-98. Crossref

26. Malessy MJA, de Ruiter GCW, de Boer KS, Thomeer RTWM. Evaluation of suprascapular nerve neurotization after nerve graft or transfer in the treatment of brachial plexus traction lesions. J Neurosurg 2004;101(3):377-89. Crossref

27. Suzuki K, Doi K, Hattori Y, Pagsaligan JM. Long-term results of spinal accessory nerve transfer to the suprascapular nerve in upper-type paralysis of brachial plexus injury. J Reconstr Microsurg 2007;23(06):295-9. Crossref

28. Oberlin C, Beal D, Leechavengvongs S, Salon A, Dauge MC, Sarcy JJ. Nerve transfer to biceps muscle using a part of ulnar nerve for $\mathrm{C} 5-\mathrm{C} 6$ avulsion of the brachial plexus: anatomical study and report of four cases. J Hand Surg Am 1994;19(2):2327. Crossref

29. Verdins K, Kapickis M. Oberlin's transfer: long term outcomes. J Hand Surg Asian-Pacific Vol 2018;23(02):176-80. Crossref

30. Venkatramani H, Bhardwaj P, Faruquee SR, Sabapathy SR. Functional outcome of nerve transfer for restoration of shoulder and elbow function in upper brachial plexus injury. J Brachial Plex Peripher Nerve Inj 2008;3(01):e49-57. Crossref

31. Gutowski KA, Orenstein HH. Restoration of elbow flexion after brachial plexus injury: the role of nerve and muscle transfers. Plast Reconstr Surg 2000;106(6):1348-57. Crossref

32. Liverneaux PA, Diaz LC, Beaulieu J-Y, Durand S, Oberlin C. Preliminary results of double nerve transfer to restore elbow flexion in upper type brachial plexus palsies. Plast Reconstr Surg 2006;117(3):915-9. Crossref

33. Leechavengvongs S, Malungpaishorpe $\mathrm{K}$, Uerpairojkit $\mathrm{C}, \mathrm{Ng}$ $\mathrm{CY}$, Witoonchart K. Nerve transfers to restore shoulder function. Hand Clin 2016;32(2):153-64. Crossref

34. Novak CB, Mackinnon SE. Surgical treatment of a long thoracic nerve palsy. Ann Thorac Surg 2002;73(5):1643-5. Crossref

35. Uerpairojkit C, Leechavengvongs S, Witoonchart K, Malungpaishorpe K, Raksakulkiat R. Nerve transfer to serratus anterior muscle using the thoracodorsal nerve for winged scapula in C5 and C6 brachial plexus root avulsions. J Hand Surg Am 2009;34(1):74-8. Crossref 